\title{
A comparative thermogravimetric study of waterlogged archaeological and sound woods
}

\author{
G. Cavallaro • D. I. Donato - G. Lazzara • \\ S. Milioto
}

Cultural Heritage Special Chapter

(c) Akadémiai Kiadó, Budapest, Hungary 2010

\begin{abstract}
Waterlogged archaeological woods Pinus pinaster and Fagus sylvatica L. were analyzed by using TG technique. Degradation processes ascribable to the holocellulose decay were evidenced at nearly the same temperature for sound and archaeological samples. The residual matters at 600 and $900{ }^{\circ} \mathrm{C}$ of the sound woods are much lower than those of archaeological waterlogged woods in agreement with the presence of inorganic materials encapsulated during the burial into the marine environment. It was proposed a new protocol to rapidly calculate the maximum water content parameter, which is related to the wood degradation state. TG experiments at variable heating rates were performed to obtain kinetic parameters for the degradation process. The Flynn-WallOzawa and Friedman approaches allowed us to calculate the activation energy, which is significantly different for the sound and the archaeological woods.
\end{abstract}

Keywords TG $\cdot$ SEM $\cdot$ Waterlogged archaeological wood $\cdot$ Sound wood $\cdot$ Activation energy $\cdot$ MWC

\section{Introduction}

Within the cultural heritage topic, the wood occupies a relevant position because of its large presence in several art-works. Specifically, the waterlogged woods, coming from wet environments, constitute a complex matter as they undergo to serious damages if dried. Of course,

G. Cavallaro · D. I. Donato · G. Lazzara $(\bowtie) \cdot$ S. Milioto Dipartimento di Chimica Fisica "F. Accascina", Università degli Studi di Palermo, Viale delle Scienze, Parco D’Orleans II, 90128 Palermo, Italy

e-mail: g.lazzara@unipa.it methodologies for their conservation and preservation are necessary $[1,2]$. One of the most important aspect in the conservation process deals with the loss of water from the waterlogged wood which shrinks and deforms the material. Therefore, it is necessary that the water filling wood cavities is replaced by consolidants.

For a correct conservation process, a deep knowledge of the waterlogged wood state is required and to be rather exhaustive several techniques should be used. Py-GC/MS was applied to the study of lignin and cellulose in order to investigate decay processes in aged woods [3, 4]. CPMASNMR technique was applied to archaeological samples from the eleventh century excavation site at the Lake Paladru at Charavines (France) [5]. Recently, a multianalytical study of lignin in archaeological woods of samples collected from the Site of the Ancient Ships of San Rossore (Pisa, Italy), was done by using phosphorus NMR spectroscopy, two-dimensional NMR spectroscopy and GPC analysis [6, 7]. Degradation of cellulose is the main responsible of woods alteration so that artificial ageing of woods was also done by immerging fir and chestnut woods into deionised water and into artificial sea water for several weeks even in the presence of $\mathrm{Cu}$ and $\mathrm{Fe}$ [8]. This study used the TG, DSC, X-ray diffraction, and X-ray fluorescence techniques. TG continuously increases in application to several archaeological woods [8-11]. Furthermore, we have previously shown that the consolidation of archaeological woods may be monitored by thermogravimetry, which enabled us to evidence quantitatively the impregnants entrapped into the wood and to discriminate the affinity of consolidants differently sized toward the micropores of the cell wall wood [9].

Within this issue, we thought it would be interesting to give some light to the characterization of archaeological waterlogged woods by means of thermogravimetry, which 
has been revealed a proper and suitable technique for this purpose. In particular, we will study wood samples (Pinus pinaster and Fagus sylvatica L.) from the ship Chrétienne C, (II century, BC), discovered over the coast of Provence (France) and the sound woods of the same taxa. TG experiments at fixed heating rate will be carried out to compare the thermal stability of archaeological and sound woods. Moreover, it will be verified whether it is possible to calculate from TG measurements the maximum water content parameter, which reflects the degradation state of the wood samples, usually computed by means of a gravimetric method [12]. TG experiments at variable heating rates will be performed to obtain kinetic parameters for the degradation process.

\section{Materials and samples}

Sound woods are Pinus pinaster purchased from the Carolina Biological Supply Company and Fagus sylvatica L. supplied by IVALSA CNR (Florence).

The waterlogged archaeological woods are from the ship Chrétienne C, (II century, BC), discovered over the coast of Provence and were kindly provided by Prof. Patrice Pomey of C.N.R.S., Université de Provence (France).

The archaeological woods were characterized according to the procedure of the Italian standard UNI 11205:2007; the identification of taxon wood and the decay assessment determined from the maximum water content (MWC) are reported elsewhere [9].

\section{Thermogravimetric analysis}

The measurements were performed by means of a TGA Q5000 IR apparatus (TA Instruments) under nitrogen flow of $25 \mathrm{~cm}^{3} \mathrm{~min}^{-1}$ for the sample and $10 \mathrm{~cm}^{3} \mathrm{~min}^{-1}$ for the balance. The investigated temperature range was comprised between 25 and $900{ }^{\circ} \mathrm{C}$ at variable heating rates. We determined the first order differentiation curves of mass loss to temperature (DTG) from the temperature dependence of mass loss (TG). The decomposition temperature $\left(t_{\mathrm{d}}\right)$ was calculated from the DTG peaks and shoulders. The mass loss was estimated from the area of the peaks exhibited by the DTG curves. The sample weight was ca. $5 \mathrm{mg}$. Each measurement was repeated twice at least. The accuracy on $t_{\mathrm{d}}$ and on residual mass is $\pm 2{ }^{\circ} \mathrm{C}$ and $\pm 3 \%$, respectively.

Scanning electron microscopy

Micrographs and energy dispersive X-ray spectrum (EDX) of archaeological wood were obtained by using a microscope ESEM FEI QUANTA 200F. For the morphology, the surface of the sample was coated with gold in argon by means of an Edwards Sputter Coater S150A to avoid charging under electron beam. The EDX spectrum was registered on the uncoated sample to avoid that the peaks of gold superimpose with eventual peaks of other elements present in the sample.

\section{Results and discussion}

Thermal stability of sound and archaeological woods

TG experiments were performed on the wood samples equilibrated at relative humidity $(\mathrm{RH})$ of $50 \%$ and room temperature; the waterlogged woods were dried at $103{ }^{\circ} \mathrm{C}$ before the equilibration. Figures 1 and 2 illustrate the TG and DTG curves at the heating rate of $10{ }^{\circ} \mathrm{C} \mathrm{min}-1$ for both the sound and the waterlogged archaeological woods, respectively. As concerns the sound woods, the DTG curves are rather similar as a comparable mass loss at ca. $100{ }^{\circ} \mathrm{C}$ is detected and ascribable to water removal. Moreover, each wood exhibits a peak around $380{ }^{\circ} \mathrm{C}$ and a shoulder at ca. $300{ }^{\circ} \mathrm{C}$, which is more evident for $F$. sylvatica L. Obviously, the peculiarities at high temperatures evidence thermal degradation processes.

The archaeological samples exhibit rather different profiles of the DTG curves. Apart from the weight loss at ca. $100{ }^{\circ} \mathrm{C}, P$. pinaster exhibits a peak around $300{ }^{\circ} \mathrm{C}$, a

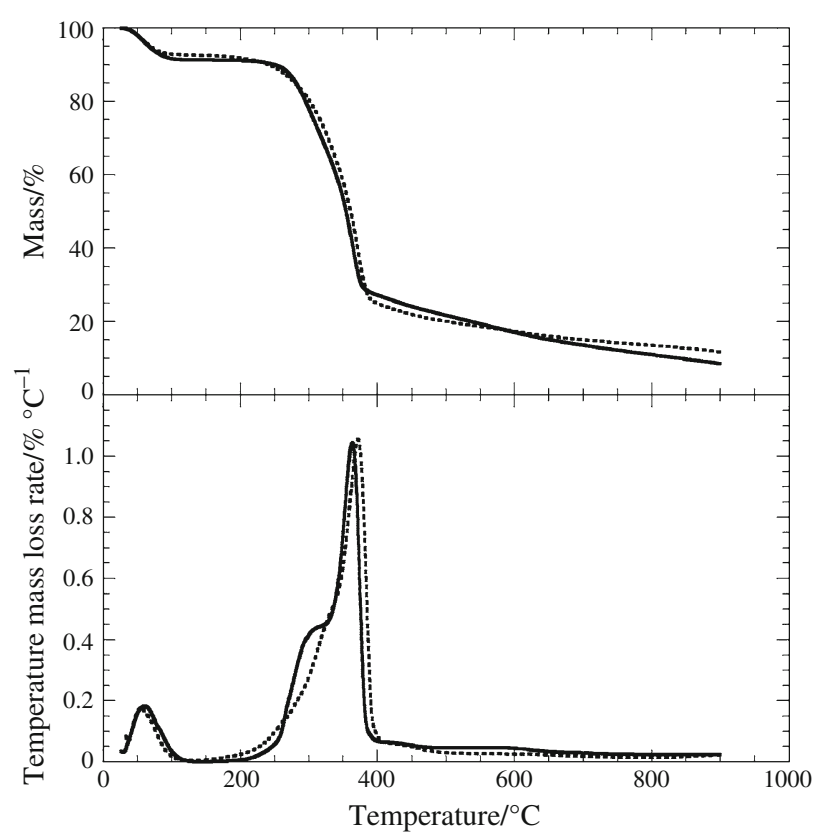

Fig. 1 Curves of mass loss to temperature (TG) and first order differentiation curves of mass loss to temperature (DTG) for Pinus pinaster (dotted line) and Fagus sylvatica L. (solid line) sound woods at the heating rate of $10^{\circ} \mathrm{C} \mathrm{m^{-1 }}$ 


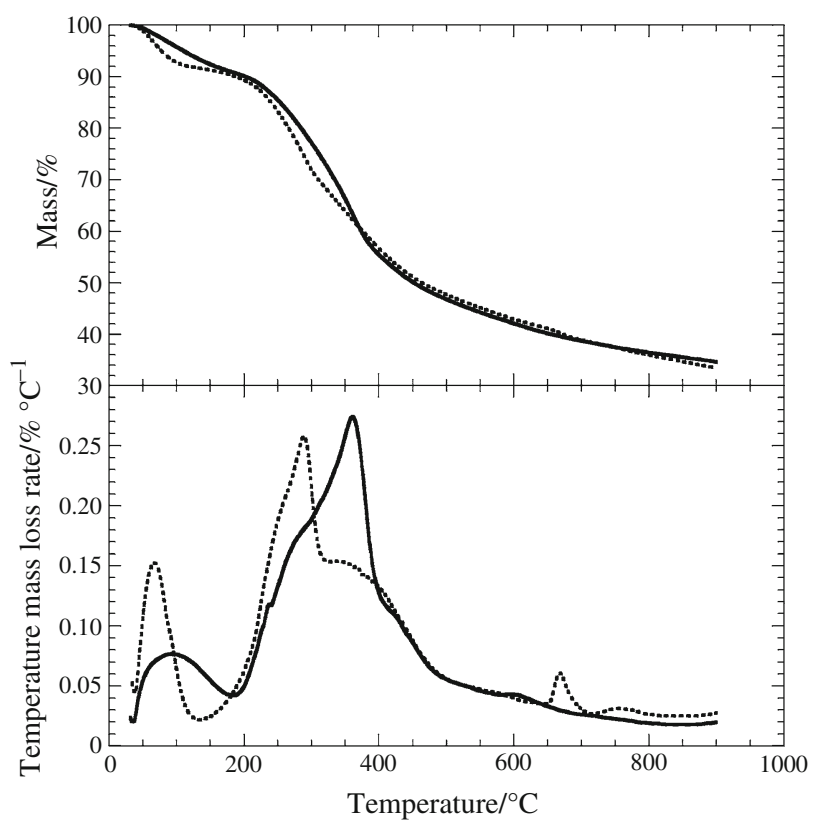

Fig. 2 Curves of mass loss to temperature (TG) and first-order differentiation curves of mass loss to temperature (DTG) for Pinus pinaster (dotted line) and Fagus sylvatica L. (solid line) archaeological woods at the heating rate of $10{ }^{\circ} \mathrm{C} \mathrm{min}-1$

pronounced shoulder at $350{ }^{\circ} \mathrm{C}$. In the case of $F$. sylvatica L., the DTG curve shows the water elimination, a peak at about $350{ }^{\circ} \mathrm{C}$.

The moisture content calculated as grams of water divided by grams of dried wood (MC), the residual matter, which is the non-degraded wood, present between 150 and $600{ }^{\circ} \mathrm{C}\left(\mathrm{RM}_{600}\right)$ and between 150 and $900{ }^{\circ} \mathrm{C}\left(\mathrm{RM}_{900}\right)$ and the degradation temperature $\left(t_{\mathrm{d}}\right)$ are collected in Table 1 . The water content is comparable whatever is the nature of the sample. This result is expected as all the samples are equilibrated at the same humidity and temperature. Under nitrogen flow, for archaeological woods the residual is ca. $45 \%$ that is in a good agreement with our previous results [9] corroborating the reliability of the obtained results. For sound woods, the $\mathrm{RM}_{600}$ values are comparable and lower than those of archaeological woods with the same taxa. A similar behavior is also exhibited at $900{ }^{\circ} \mathrm{C}$ where $\mathrm{RM}_{900}$ of sound woods assumes values around $10 \%$ and $\mathrm{RM}_{900}$ of archaeological woods do values of ca. 35\%. The larger $\mathrm{RM}_{900}$ for archaeological woods may reflect the encapsulation of inorganic materials occurred during the burial into the marine environment. In fact, inorganic substrates replace organic matter; phosphate and silicates have been detected into petrified wood and calcium minerals in wood buried in terrestrial region. In our case, iron species may be found because our samples are originated from a ship that also contains iron objects [13]. This expectation is confirmed by SEM micrographs illustrated in Fig. 3. In fact, from the morphology of the $F$. sylvatica $\mathrm{L}$. archaeological
Table 1 Thermal properties of sound and archaeological woods

\begin{tabular}{llllll}
\hline & \multicolumn{2}{l}{ Sound woods } & & \multicolumn{2}{l}{ Archaeological woods } \\
\cline { 2 - 3 } & $\begin{array}{l}\text { Pinus } \\
\text { pinaster }\end{array}$ & $\begin{array}{l}\text { Fagus } \\
\text { sylvatica }\end{array}$ & & $\begin{array}{l}\text { Pinus } \\
\text { pinaster }\end{array}$ & $\begin{array}{l}\text { Fagus } \\
\text { sylvatica } \text { L. }\end{array}$ \\
\hline MC & 9.0 & 9.3 & 9.2 & 8.5 \\
$\mathrm{RM}_{600}$ & 17.3 & 17.0 & & 42.9 & 42.0 \\
$\mathrm{RM}_{900}$ & 11.7 & 8.8 & & 33.1 & 34.6 \\
$t_{\mathrm{d}}$ (first step) & 328 & 301 & & 289 & 279 \\
$t_{\mathrm{d}}$ (second step) & 373 & 364 & & 386 & 362 \\
\hline
\end{tabular}

Samples dried at $103{ }^{\circ} \mathrm{C}$ and equilibrated at room temperature and RH 50\%. Units are: $\mathrm{MC}, \mathrm{RM}_{600}$ and $\mathrm{RM}_{900}, \mathrm{wt} \% ; t_{\mathrm{d}},{ }^{\circ} \mathrm{C}$

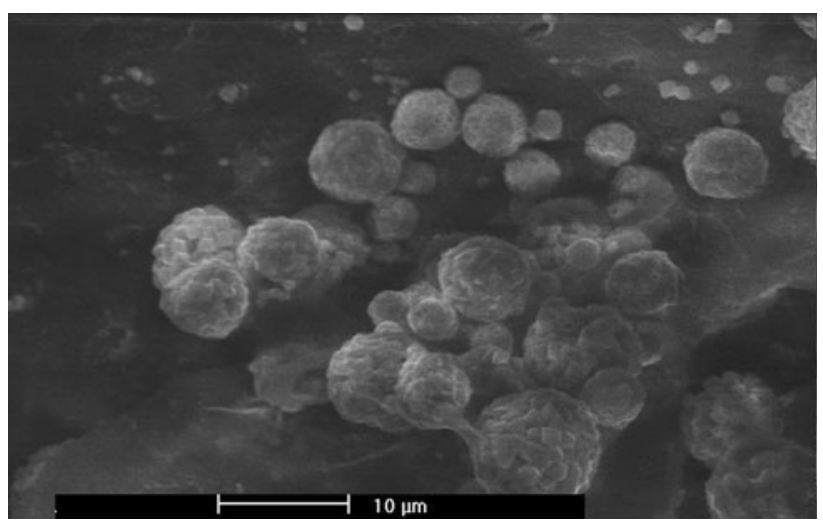

Fig. 3 Scanning electron microscopy image for Fagus sylvatica L. archaeological wood

Table 2 Elemental EDX microanalysis of Fagus sylvatica $L$. archaeological wood

\begin{tabular}{lrr}
\hline Element & wt\% & at.\% \\
\hline C K & 60.67 & 73.05 \\
O K & 24.44 & 22.09 \\
S K & 3.32 & 1.50 \\
Ca K & 3.58 & 1.29 \\
Fe K & 8.00 & 2.07 \\
\hline
\end{tabular}

Data are expressed as both weight (wt\%) and atomic (at.\%) percent

wood sample, one can identify the presence of pyrite, which appears like a framboidal structure characterized by roughly spherical aggregates (ca. $10 \mu \mathrm{m}$ in diameter) of discrete equi-regular euhedral microcrystallites $(0.5 \mu \mathrm{m}$ in diameter) [14]. The EDX spectra evidenced the presence of carbon, oxygen, sulfur, calcium, and iron (Table 2). Therefore, the present results are consistent with species composed of iron and sulfur in agreement with literature findings [15].

As concerns $t_{\mathrm{d}}$ of sound woods, the values of the shoulder and the maximum of $P$. pinaster are ca. $10-20{ }^{\circ} \mathrm{C}$ larger than those of $F$. Sylvatica L. highlighting that the former is thermally more stable. 
A straightforward interpretation of the $t_{\mathrm{d}}$ values cannot be done because the thermal stability of the main constituents of the wood (holocellulose, lignin and so on) depend on several factors. As concerns the thermal decomposition of cellulose in wood several models have been proposed; for instance, it was assumed that the degradation may take place along the fibers or that the cellulose crystallite may start to decompose maintaining unaltered other ones [16]. Moreover, the crystalline index (CI) plays a relevant role. Three cellulose samples (Halocynthia $\mathrm{CI}=0.74$, cotton $\mathrm{CI}=0.58$ and Funacel $\mathrm{CI}=0.54$ ) showed DTG peaks centered at 341,366 , and $389{ }^{\circ} \mathrm{C}$, respectively. Rather complex is also the behavior of lignin, which depends on the wood species. Thus, the Larch lignin $\left(t_{\mathrm{d}}=343{ }^{\circ} \mathrm{C}\right)$ is more thermally stable than the Manchurian ash lignin $\left(t_{\mathrm{d}}=317^{\circ} \mathrm{C}\right)$ [17]. On this basis, one may suppose that for both samples the sharp peak and the shoulder reflect the decomposition of holocellulose and lignin.

Interesting insights may be drawn comparing sound and archaeological woods. In particular, as concerns the Pinus, the first step takes place at rather different values while the second one does at comparable temperatures (Table 1). This is also verified for the Fagus.

Properly designed TG experiments allowed us to calculate the MWC parameter, which is related to the degradation state of waterlogged wood samples. The most common procedure is based on the gravimetric method from which the water content in the wood can be determined according to the following equation [12]

$\mathrm{MWC}=100 *\left(W_{1}-W_{2}\right) / W_{2}$

where $W_{1}$ is the weight of the waterlogged wood sample saturated with water, $W_{2}$ is the weight of the sample dehydrated at $105{ }^{\circ} \mathrm{C}$. To obtain reliable results such a method requires that $10 \mathrm{~g}$ at least of sample must be analyzed. Recently, an alternative method based on NMR measurements was proposed; it determines the proton density in liquids and, in particular, the moisture content of the wood sample can be determined instantaneously from its mass and the amplitude of its NMR free-inductiondecay [18]. In the following, we will describe a rapid and accurate method based on the TG measurements. Briefly, a few $\mathrm{mg}$ of samples saturated with water are analyzed from 25 to $150{ }^{\circ} \mathrm{C}$ (Fig. 4). The obtained MWC for Pinus and Fagus waterlogged woods are $572 \pm 25$ and $637 \pm 30$, respectively, which agree well with those provided by gravimetric method (550 and 652, respectively) [9]. This procedure is fruitful because a very small amount of wood is required (a few $\mathrm{mg}$ ) and the experiment is performed within a few minutes in contrast to the gravimetric method, which needs ca. $10 \mathrm{~g}$ of sample and ca. $24 \mathrm{~h}$ for the experiment.

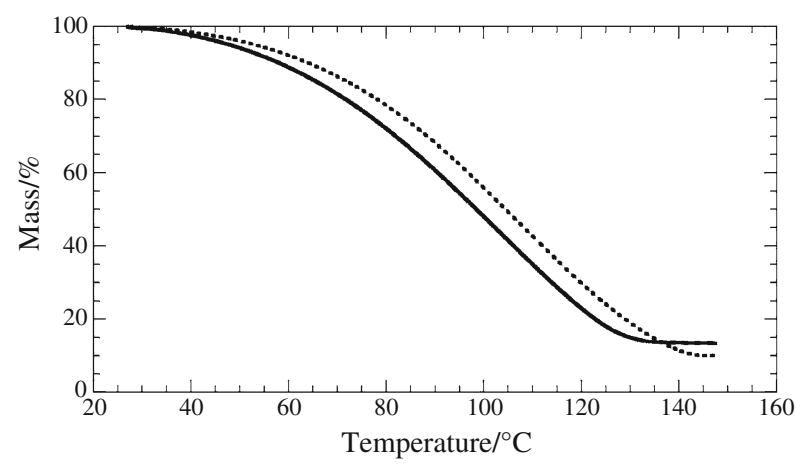

Fig. 4 Curves of mass loss to temperature for the water saturated Pinus pinaster (dotted line) and Fagus sylvatica L. (solid line) archaeological woods at the heating rate of $10{ }^{\circ} \mathrm{C} \min ^{-1}$ from 25 to $150{ }^{\circ} \mathrm{C}$

Kinetics of wood thermal degradation

Some examples of TG data at different heating rates $(\beta)$ for a given wood sample are illustrated in Fig. 5. It is well known that combining the results from TG measurements at different $\beta$ values, one obtains information on the kinetics of the thermal degradation process. Generally, the onset of the degradation temperatures is moved toward larger value by increasing $\beta$ probably because the process is kinetically controlled. The TG data collected at various $\beta$ can be treated to determine the activation energy of degradation of the woods. To this aim, we used the FlynnWall-Ozawa approach (FWO), which is a non-isothermal model-free method, to calculate the activation energy $\left(E_{\mathrm{a}}\right)$ as a function of the extent of conversion $(\alpha)$ without making any assumption on the reaction mechanism. For this reason, the FWO method is widely used in kinetic studies of thermal decomposition of polymers [19-22]. Equation 2 was employed

$\ln \beta=\left[\frac{A E_{a}}{R G(\alpha)}\right]-5.33303-1.0516 \frac{E_{\mathrm{a}}}{R T}$

where $G(\alpha)$ is a function of the extent of conversion, $A$ is the pre-exponential factor, while $R$ is the gas constant, and $T$ is the absolute temperature. At a given $\alpha$ value, from the slope of $\ln \beta$ versus $1 / T$ plot one can easily calculate $E_{\mathrm{a}}$. Examples of such graphs are illustrated in Fig. 6 for Fagus sound wood evidencing that a good straight line between $\ln \beta$ and $1 / T$ can be drawn. A satisfactory linearity was also obtained for other samples.

The obtained $E_{\mathrm{a}}$ values as functions of $\alpha$ are plotted in Fig. 7 for the sound and the archaeological wood samples. In the case of sound woods, the $E_{\mathrm{a}}$ values are independent of the wooden Taxon and $\alpha$. They are in agreement with those reported in the literature [23] for wood-pine $\left(162 \mathrm{~kJ} \mathrm{~mol}^{-1}\right)$ and wood-maple $\left(156 \mathrm{~kJ} \mathrm{~mol}^{-1}\right)$ and very close to the $E_{\mathrm{a}}$ values of three samples of cellulose (165, 


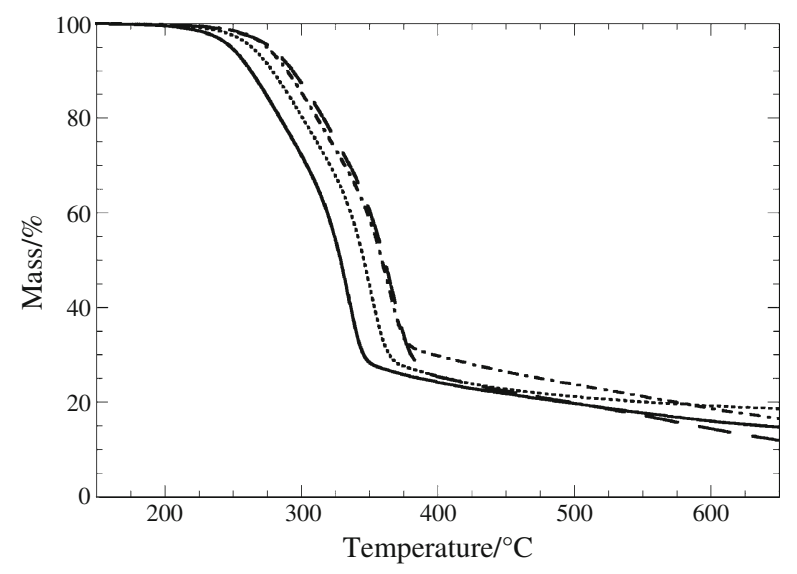

Fig. 5 Curves of mass loss to temperature for Fagus sylvatica L. sound woods at heating rate of (solid line), $2{ }^{\circ} \mathrm{C} \min ^{-1}$; (dotted line), $5{ }^{\circ} \mathrm{C} \min ^{-1}$, (dotted dashed line), $10{ }^{\circ} \mathrm{C} \min ^{-1}$ and (broken line), $15^{\circ} \mathrm{C} \min ^{-1}$

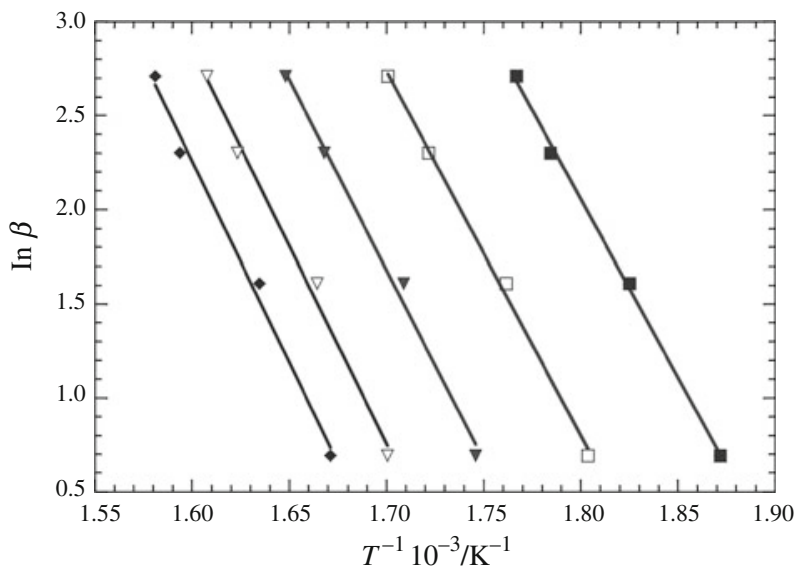

Fig. 6 Dependence of $\ln \beta$ on $1 / T$ according to Eq. 2 for Fagus sylvatica $\mathrm{L}$. sound woods at the $\alpha$ values of (filled square), 0.1; (open square), 0.2; (filled inverted triangle), 0.3; (inverted triangle), 0.4 and (filled diamond), 0.5

159, and $166 \mathrm{~kJ} \mathrm{~mol}^{-1}$ for Halocynthia, cotton and Funacel, respectively), which differ for the crystal structure [16]. This indicates that our $E_{\mathrm{a}}$ values reflect the cellulose decomposition, which involves the same energy effect whatever is the taxon or cellulose degree crystallinity.

It is worth-noting that for the archaeological woods $E_{\mathrm{a}}$ is not constant with $\alpha$ change. This result may be a limit of the FWO method so that we decided to analyze our data with the isoconversional Friedman's method being more accurate than the FWO method for variant activation energies [24]. Therefore, the following equation was used

$\ln \left(\frac{\mathrm{d} \alpha}{\mathrm{d} T} \beta\right)=\ln [A f(\alpha)]-\frac{E_{\mathrm{a}}}{R T}$

where $\mathrm{d} \alpha / \mathrm{d} T$ is the first derivative of $\alpha$ with temperature, and $f(\alpha)$ is a function of the extent of conversion that

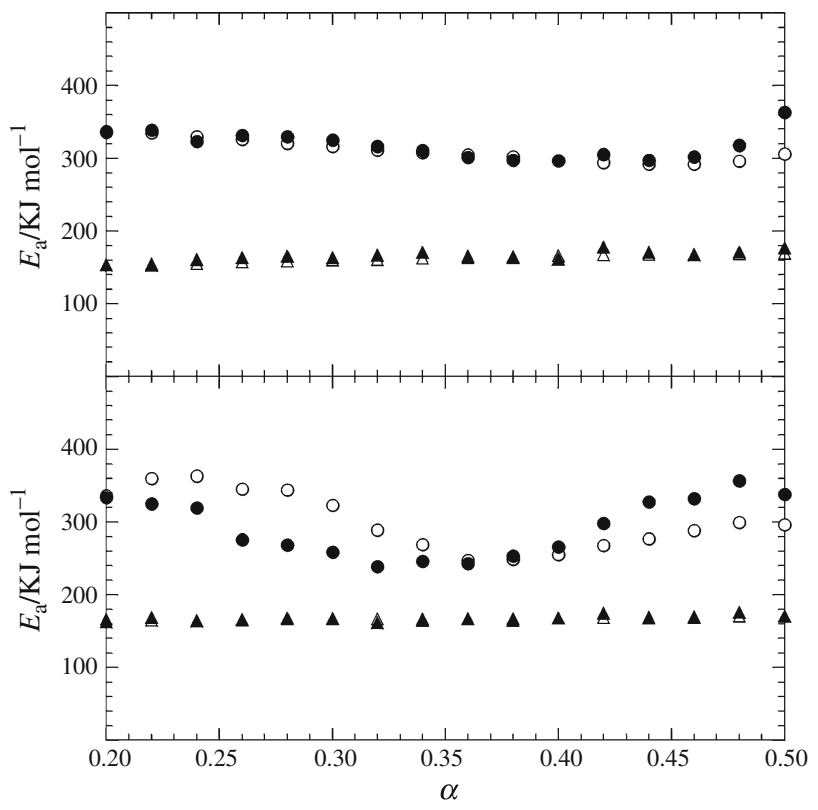

Fig. 7 Activation energy of degradation as a function of degree of conversion for Fagus sylvatica L. (top) and Pinus pinaster (bottom) archaeological (circle) and sound (triangle) woods. Empty and filled symbols refer to data obtained by using Eqs. 2 and 3, respectively

depends on the degradation mechanism. It is worth-noting that the $E_{\mathrm{a}}$ values obtained by means of the two methods are very similar (Fig. 7) with the exception of the P. pinaster archaeological wood, which showed the largest $E_{\mathrm{a}}$ change with $\alpha$. Nevertheless, the following general conclusions on the $E_{\mathrm{a}}$ values can be drawn.

For a given $\alpha$, the $E_{\mathrm{a}}$ value for the archaeological wood is larger than that of $E_{\mathrm{a}}$ of the corresponding sound wood. This result is interesting because: (1) it may give insight on the thermal degradation behavior of woods, and (2) it might be considered a new parameter for the classification of wood samples in dependence of their degradation state. In principle, one may argue that the component, which degrades with a lower activation energy is lost over time, and therefore the remained organic materials, most stable components, determine the larger $E_{\mathrm{a}}$ values in agreement with the experimental results for archaeological woods (Fig. 7). The increase of $E_{\mathrm{a}}$ for the archaeological woods might reflect the different holocellulose/lignin ratio compared to the sound woods. However, $E_{\mathrm{a}}$ values ranging between 130 and $170 \mathrm{~kJ} \mathrm{~mol}^{-1}$ for pure lignin are reported [25]. Furthermore, the chemical structure of lignin in sound and archaeological woods is rather similar [7]. One may therefore rule out that the large $E_{\mathrm{a}}$ values are controlled by the lignin content in the archaeological woods. Instead, it is likely that the inorganic material encapsulated into the wood may generate the significant differences between sound and archaeological woods in agreement with the higher $\mathrm{RM}_{900}$ values. 


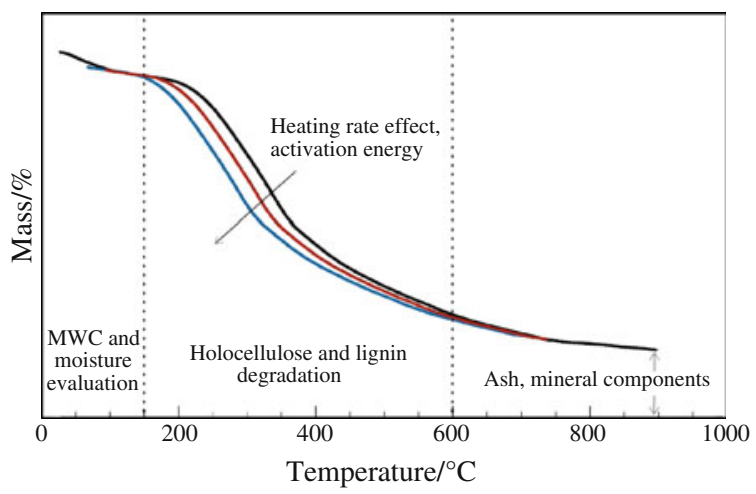

Fig. 8 Key parameters that can be calculated from TG curves of wood samples

On the relevance of the thermogravimetry applied to archaeological wood

Thermogravimetric analysis represents a powerful, lowcost, and micro-destructive method for the investigation of the conservation state of wooden findings. Several information can be drawn from TG curves looking at the different temperature domains as sketched in Fig. 8. By studying wet wood samples, the weight loss up to $150{ }^{\circ} \mathrm{C}$ related to the water content provides a fast route to calculate the MWC parameter with a few mg of sample and within a few minutes that is more convenient than the conventional gravimetric method, which is time consuming and it requires grams of sample. Moreover, the TG can be used for the characterization of small wooden findings or samples obtained from micro-coring, which are not measurable by means of the conventional method due to the limited amount. The MWC parameter is strategic in the classification of the state of conservation of an archaeological wood because it can be also related to the porosity of the wood, which is essential for choosing the procedure of consolidation [26]. The degradation steps at larger temperatures give insights on the holocellulose and lignin content, while the residual matter at $900{ }^{\circ} \mathrm{C}$ is related to the mineral matter present into the wood. Measurements carried out at variable heating rates provide the activation energy for the degradation process. In addition, we recently showed [9] that TG technique applied to consolidated wood provides accurate evaluation of the percentage of consolidant encapsulated into the cavity of the sample, it enables us to discriminate the amount of consolidants having different thermal stability and, finally, the affinity of consolidants differently sized towards the micropores of the cell wall wood.

Acknowledgements The work was financially supported by the University of Palermo. We thank the "Fondazione Banco di Sicilia" which cofinanced the TGA Q5000 IR apparatus (Convenzione PR 4.b/08).

\section{References}

1. Jordan BA. Site characteristics impacting the survival of historic waterlogged wood: a review. Int Biodeterior Biodegrad. 2001;47: $47-54$.

2. Giachi G, Capretti C, Macchioni N, Pizzo B, Donato ID. A methodological approach in the evaluation of efficacy of treatment for the dimensional stabilization of waterlogged archaeological wood. J Cult Herit. 2010;11:91-101.

3. Van Bergen PF, Imogen P, Ogilvie TMA, Caple C, Evershed RP. Evidence for demethylation of syringyl moieties in archaeological wood using pyrolysis-gas chromatography/mass spectrometry. Rapid Commun Mass Spectrom. 2000;14:71-9.

4. Popescu CM, Dobele G, Rossinskaja G, Dizhbite T, Vasile C. Degradation of lime wood painting supports evaluation of changes in the structure of aged lime wood by different physico-chemical methods. J Anal Appl Pyrolysis. 2007;79:71-7.

5. Bardet M, Foray MF. Trân QK high-resolution solid-state CPMAS NMR study of archaeological woods. Anal Chem. 2002; 74:4386-90.

6. Salanti A, Zoia L, Tolppa EL, Giachi G, Orlandi M. Characterization of waterlogged wood by NMR and GPC techniques. Microchem J. 2010;95:345-52.

7. Colombini MP, Lucejkoa JJ, Modugno F, Orlandi M, Tolppa EL, Zoia L. A multi-analytical study of degradation of lignin in archaeological waterlogged wood. Talanta. 2009;80:61-70.

8. Franceschi E, Cascone I, Nole D. Thermal XRD and spectrophotometric study on artificially degraded woods. J Therm Anal Calorim. 2008;91:119-25.

9. Donato DI, Lazzara G, Milioto S. Thermogravimetric analysis: a tool to evaluate the ability mixtures in consolidating waterlogged archaeological woods. J Therm Anal Calorim. 2010;101: 1085-91.

10. Campanella L, Tomassetti M, Tomellini R. Thermoanalysis of ancient, fresh and waterlogged woods. J Therm Anal Calorim. 1991;37:1923-32.

11. Streibel T, Geißler R, Saraji-Bozorgzad M, Sklorz M, Kaisersberger E, Denner T, Zimmermann R. Evolved gas analysis (EGA) in TG and DSC with single photon ionisation mass spectrometry (SPI-MS): molecular organic signatures from pyrolysis of soft and hard wood, coal, crude oil and ABS polymer. J Therm Anal Calorim. 2009;96:795-804.

12. Florian E (1989) Scope and history of archaeological wood Archaeological Wood, Ed American Chemical Society, Washington, DC 1990, p 8

13. Hedges JI. The chemistry of archaeological wood. In: Rowell RM, Barbour RJ, editors. Archaeological wood properties chemistry and preservation. Advances in Chemistry Series 225. Washington: American Chemical Society; 1990. p. 137

14. Wilkin RT, Barnes HL. Formation processes of framboidal pyrite. Geochim Cosmochim Acta. 1997;61:323-39.

15. Fors Y, Nilsson T, Risberg ED, Sandstrom M. Torssander $P$ Sulfur accumulation in pinewood (Pinus sylvestris) induced by bacteria in a simulated seabed environment: implications for marine archaeological wood and fossil fuels. Int Biodeter Biodegradation. 2008;62:336-47.

16. Kim UJ, Eom SH, Wada M. Thermal decomposition of native cellulose: influence on crystallite size. Polym Degrad Stab. 2010;95:778-81.

17. Li J, Lib B, Zhang X. Comparative studies of thermal degradation between larch lignin and manchurian ash lignin. Polym Degrad Stab. 2002;78:279-85.

18. Merela M, Oven P, Sersa I, Mikac U. A single point NMR method for instantaneous determination of the moisture content of wood. Holzforschung. 2009;63:348-51. 
19. Wang SX, Tan ZC, Li YS, Sun LX, Li Y. A kinetic analysis of thermal decomposition of polyaniline $/ \mathrm{ZrO}_{2}$ composite. J Therm Anal Calorim. 2008;92:483-7.

20. Yu-Hsiang H, Chuh-Yung C, Cheng-Chien W. Viscoelastic properties and thermal degradation kinetics of silica/PMMA nanocomposites. Polym Degrad Stab. 2004;84:545-53.

21. Pielichowski K, Flejtuch K. Non-oxidative thermal degradation of poly(ethylene oxide): kinetic and thermoanalytical study. J Anal Appl Pyrolysis. 2005;73:131-8.

22. Budrugeac P, Segal E, Pérez-Maqueda LA, Criado JM. The use of the IKP method for evaluating the kinetic parameters and the conversion function of the thermal dehydrochlorination of PVC from non-isothermal data. Polym Degrad Stab. 2004;84:311-20.

23. Yao F, Wu Q, Lei Y, Guo W, Xu Y. Thermal decomposition kinetics of natural fibers: activation energy with dynamic thermogravimetric analysis. Polym Degrad Stab. 2008;93:90-8.
24. Criado JM, Sanchez-Jimenez PE, Perez-Maqueda LA. Critical study of the isoconversional methods of kinetic analysis. J Therm Anal Calorim. 2008;92:199-203.

25. Jiang G, Nowakowski DJ, Bridgwater AV. A systematic study of the kinetics of lignin pyrolysis. Thermochim Acta. 2010;498: 61-6.

26. Donato ID, Armata N. Physical properties of waterlogged wood measurements with Accupyc 1330, Helium picnometer. In: Straetkvern K, Huisman DJ, editors. Proceedings of the 10th ICOM Group on wet organic archaeologic materials conference, Amsterdam. Amersfoort: Nederlandse Archeologische Rapporten, Drukkerij Stampij 2007;37:79-88. 